The current service depends on the goodwill of unpaid volunteers and is relatively inexpensive to run. The voluntary agency can offer confidentiality more readily than any statutory service which may be bound to disclose information according to Child Health Legislation. However, all agencies do agree on a general policy to protect young people and do the upmost to minimise danger. More than the statutory services, voluntary agencies can offer various forms of assistance without the same need to justify or demonstrate cost-effectiveness. At the present time there is a reluctance to gather information from young people, which he or she may be reluctant to give. There is not a strong emphasis on counting the numbers and types of problems seen and measuring outcome. The volunteers are not demanding better working environments or worried about litigation. If the voluntary agencies were to address these organisational short-comings, the increasing bureaucracy might be detrimental to the friendly and informal accessibility of the current disparate service and spoil the most useful component for the troubled anti-establishment adolescent.

It would seem logical that all services attempting to meet the need of the growing number of adolescents with emotional problems should have some knowledge of the different types of provision. In times when resources are scarce it would make sense to use all that is avallable to young people. Despite the limited resources of the adolescent counselling services, young people are seeking out these agencies in increasing numbers. The work of unpaid volunteers should be acknowledged by health professionals who might sometimes benefit from joint working. Voluntary services might fill the gap left by inadequately funded statutory services, but without an organised system of evaluation the voluntary sector can only be described at the local level. Each professional would have to investigate the agency in his or her area. Good working relations may be possible but all involved would need to remain clear about their abilities and limitations and to concentrate their efforts on increasing appropriate resources. Any attempt to evaluate and organise such voluntary agencies might spoil that part which is essential to their success.

\section{References}

MABEY, J. G. \& SORENSEN, B. (1995) Counselling for Young People. Oxford: Oxford University Press.

WILLIAMS, R. (1995) Together We Stand: The Commissioning Role and Management of Child and Adolescent Services. London: HMSO.

YOUTH ACCESS (1996) Core Principles. London: Youth Access.

Mary Mitchell, Senior Registrar, Child and Adolescent Psychiatry Department, G level, Southampton General Hospital, Tremona Road, Southampton SO16 6YD

\title{
Readability of user leaflets
}

\author{
Harriet Humfress and Ulrike Schmidt
}

\begin{abstract}
Aims and method Leaflets are commonly used as a way of providing information to users. In this study, we use a simple index of 'readability' to compare a range of leaflets available to people with mental health problems.

Results The majority of the leaflets contained passages that are likely to be beyond the comprehension of people with mental health problems. Clinical implications Leaflets are a cost-effective way of providing information, but only if the text can be understood by the target audience.
\end{abstract}

Much emphasis has recently been put on increasing user involvement in psychiatric care. One aspect of this is to give users more information to help them understand their illness and to explain about different treatment options and services available to help them. An economic way of providing users with such information is by way of written material in the form of leaflets or factsheets.

Over about the past eight years, the Royal College of Psychiatrists has published 14 patient factsheets and 10 'Help is at Hand' leaflets on a variety of psychiatric disorders and their treatment. Many users may, however, prefer more independent information other than from a professional body and MIND has also published a similar series of leaflets. For patients detained under the Mental Health Act 1983, written 
information must be provided by law to inform patients of their rights and describe the procedures that will be followed. Since the Community Care Act 1991 came into action and, more recently, supervision registers and supervised discharge, many provider units have devised user leaflets for patients to explain how this legislation might affect them.

Many users of mental health services will have reduced attention and concentration and other forms of cognitive impairment. Many will also have experienced poor or disrupted education. These problems are likely to affect patients' ability to take on board written information and understand it. In this study, we evaluate a range of leaflets targeted at people with mental health problems. We hypothesised that leaflets written by professionals for users (Royal College of Psychiatrists, Mental Health Act, etc.) would be less readable than those written by MIND.

\section{The study}

A sample of literature available to users of mental health services was studied: all currently available patient information factsheets produced by the Royal College of Psychiatrists (April 1997 versions); all Help is at Hand leaflets produced by the Royal College of Psychiatrists; leaflets produced by MIND ('Understanding...' series); Mental Health Act 1983 leaflets and information sheets for service users about the Care Programme Approach (CPA), supervised discharge and the supervision register from two inner London Mental Health Trusts (Trust I and Trust II).

We used the Gunning FOG (frequency of gobbledegook; Henessy, 1989) test to compare the readability of the documents. A reading score' was calculated, based on the number of long sentences and long words in a sample of text (see Appendix). The most complex passage was selected. Similar studies have found this to be a useful measure (Albert \& Chadwick, 1992; Petterson, 1994). Table 1 lists the reading scores of documents from a variety of sources.

The style of the document was also noted, including size of print, type of print (e.g. bold

Table 1. Reading scores of documents from various forms of writing (adapted from Albert \& Chadwick, 1992)

\begin{tabular}{lc}
\hline & Score \\
\hline Arthur Hailey (Strong Medicine) & 7 \\
Sunday People (news story) & 10 \\
Kingsley Amis (The Old Devils) & 11 \\
Daily Mail (news story) & 12 \\
British Medical Journal article (on stroke) & 15 \\
The Times leader & 17 \\
Insurance policy & 20
\end{tabular}

Table 2. Reading scores of the Royal College of Psychiatrists patient information factsheets

\begin{tabular}{ll}
\hline Patient information factsheet & $\begin{array}{l}\text { Peak } \\
\text { score }\end{array}$ \\
\hline $\begin{array}{ll}\text { Schizophrenia: what you should know } \\
\text { Mental illness after childbirth: what you } \\
\text { should know }\end{array}$ & 17 \\
Depression in men: what you should know & 16 \\
Alcohol: what you should know & 11 \\
Depot medication: what you should know & 13 \\
ECT (electroconvulsive therapy): what you & 13 \\
should know & 12 \\
Lithium therapy: what you should know & 14 \\
Tranquillisers and sleeping tablets: what you & 14 \\
should know & \\
Control and restraint: what you should know & 17 \\
Patients' rights and moneys: what you should & 12 \\
know & 19 \\
What is a psychiatrist?. What is a & \\
psychologist? & 12 \\
The psychiatric team: what you should know & 12 \\
Psychotherapy: what you should know & 14 \\
Cognitive therapy: what you should know & 14 \\
Median (range) & 13.5 \\
& $(11-19)$ \\
\hline
\end{tabular}

or italics) and effective use of colour and illustrations.

\section{Findings}

The reading scores of complex passages from the leaflets are given in Tables 2-6. As a guideline to interpreting these scores, Albert \& Chadwick (1992) suggest that leaflets designed for the general public should have a reading score of 11 or below.

\section{Royal College of Psychiatrists}

All of the patient information factseets bar one contained text with a reading score of 12 or above

Table 3. Reading scores of the Royal College of Psychiatrists "Help is at Hand" leaflets

\begin{tabular}{ll}
\hline & Peak \\
'Help is at Hand' leafiets & score \\
\hline Bereavement & 12 \\
Depression & 13 \\
Depression \& alcohol & 13 \\
Depression in the elderly & 11 \\
Depression in people with learning disability & 15 \\
Depression in the workplace & 15 \\
Manic depressive illness & 12 \\
Postnatal depression & 13 \\
Schizophrenia & 14 \\
Social phobias & 11 \\
Median (range) & 13 \\
\end{tabular}


Table 4. Reading scores of the MIND leaflets

\begin{tabular}{ll}
\hline Leaflet ('Understanding ....) & Peak score \\
\hline Schizophrenia & 14 \\
Manic depression & 18 \\
Depression & 12 \\
Anxiety & 12 \\
Phobias and obsessions & 18 \\
Post-traumatic stress disorder & 16 \\
Self-harm & 13 \\
Childhood distress & 16 \\
Eating distress & 15 \\
Dementia & 18 \\
Bereavement & 12 \\
Talking treatments & 14 \\
Median (range) & $15(12-18)$ \\
\hline
\end{tabular}

(see Table 2). Four (28\%) included a passage with a score of 15 or above. This is as complex as a paper from the British Medical Journal.

However, most factsheets did contain large sections which were clearly and simply written. using appropriate headings, bullet points and summary tables.

We were surprised to see that the leaflet for schizophrenia was among the most difficult to read (containing passages that were more difficult than The Times leader). The following

Table 5. Reading scores of the Mental Health Act 1983 leaflets

\begin{tabular}{|c|c|}
\hline Leoffet & $\begin{array}{l}\text { Peak } \\
\text { score }\end{array}$ \\
\hline Leaflet 1: Section $5(4)$ & 10 \\
\hline Leaflet 2: Section 4 & 12 \\
\hline Leaflet 3: Section $5(2)$ & 12 \\
\hline Leaflet 4: Section 135 & 12 \\
\hline Leaflet 5: Section 136 & 12 \\
\hline Leaflet 6: Section 2 & 11 \\
\hline Leaflet 7: Section 3 & 12 \\
\hline $\begin{array}{l}\text { Leaflet 8: Hospital order (without a } \\
\text { restriction order) (Section 37) }\end{array}$ & 10 \\
\hline $\begin{array}{l}\text { Leaflet 9: Hospital order with restrictions } \\
\text { (Sections } 37 \text { and } 41 \text { ) }\end{array}$ & 16 \\
\hline $\begin{array}{l}\text { Leaflet } 10 \text { (non-statutory): Section } \\
7 \text { - Guardianship }\end{array}$ & 11 \\
\hline Leaflet 11: Section 37 - Guardianship order & 12 \\
\hline $\begin{array}{l}\text { Leaflet 12: Patients admitted to hospital } \\
\text { from the courts. Rights to appeal }\end{array}$ & 19 \\
\hline $\begin{array}{l}\text { Leaflet } 13 \text { (to be inserted in Leaflets } 7 \text {. } \\
8,9,15 \text { or } 16 \text { ) }\end{array}$ & 13 \\
\hline $\begin{array}{l}\text { Leaflet 14: Section } 35 \text { - Remand to } \\
\text { hospital for assessment }\end{array}$ & 11 \\
\hline $\begin{array}{l}\text { Leaflet 15: Section } 36 \text { - Remand to } \\
\text { hospital for treatment }\end{array}$ & 11 \\
\hline Leaflet 16: Section 38 - Interim hospltal order & 16 \\
\hline Leaflet 17: Sections 25A-25I & \\
\hline Median (range) & $\begin{array}{l}12.5 \\
(10-19)\end{array}$ \\
\hline
\end{tabular}

Table 6. Reading scores of the information sheets (supervised discharge, supervision register)

\begin{tabular}{ll}
\hline Leantet & $\begin{array}{l}\text { Peak score } \\
\text { (mean) }\end{array}$ \\
\hline $\begin{array}{l}\text { Supervision register (NHS Trust I) } \\
\text { Supervision register (NHS Trust II) }\end{array}$ & 19 \\
Supervised discharge (model letter from & 11 \\
responsible medical officer) (NHS Trust I) & 11 \\
Supervised discharge (model letter of & 11 \\
acceptance from health authority/ & \\
provider unit) (NHS Trust I) & \\
Care Programme Approach (NHS Trust II) & 11 \\
Median (range) & 11 (11-19) \\
\hline
\end{tabular}

passage was taken from the leaflet to describe 'negative symptoms'.

"It is fairly easy to understand that somebody is ill if they are hearing voices or talking about very strange things, however, schizophrenia also affects peoples' drive, their 'get up and go' and it can be difficult to recognise that this too is a sympton of the condition. Other 'negative' symptoms include difficulty in concentrating or being interested in anything, loss of energy, and difficulty in expressing emotions. Given these problems it is easy to understand how people with schizophrenia will often withdraw from ordinary social situations."

This could be more clearly written using shorter sentences and shorter words.

The Help is at Hand leaflets were generally written more clearly, although they still contained some complex passages. The production of these leaflets has included input from user groups and two have been awarded Plain English awards (Sleep Disorders, now out of print, and Bereavement). These leaflets used some colour and cartoons, giving them a wider general appeal. They are presented as small booklets, however the text is also small which could make it hard for people with visual impairments to read. The Royal National Institute for the Blind suggest 12 points as the minimum size for a readable typeface.

\section{MIND leaflets}

The MIND leaflets generally contain text which is more complex (see Table 3). All of the leaflets have peak reading scores of 12 or above and six (50\%) contain passages with a score of 15 or above. However, the text is divided up into useful sections and includes quotes from users.

The following passage is taken from the leaflet on dementia:

"Some doctors warn that dementia is over-diagnosed and has become a handy dustbin into which people may be dumped. For example agitation, sleeplessness, memory loss and lack of appetite are all 
symptoms of depression, yet in an elderly person such behaviour is too readily seen as dementia."

\section{This could be re-written as follows:}

Some doctors warn that too many people are being told they have dementia. They say it has become a handy dustbin into which people may be dumped. For example, you may go to the doctor with a number of problems. You are having problems sleeping. You have lost your appetite. You cannot remember things very well and you feel restless. These are all symptoms of depression. Yet, in an elderly person. these signs are too readily seen as dementia.

Similarly, this is an example of a difficult passage from the manic-depression leaflet:

"Many, but by no means all, psychiatrists argue that there is a familial or genetic component or predisposition towards developing manic depression. According to this school of thought breakdown would tend to occur after a stressful event which is thought to trigger a biochemical imbalance in the brain. Stabilising medication is seen as the most appropriate form of treatment and psychotherapy as unnecessarily stressful."

These leaflets used colour and a variety of text styles, with the main body of text printed in a typeface smaller than 12 point. Again, this is likely to reduce readability for those with visual impairments, but the information is also available on cassette.

\section{Mental Health Act 1983 leaflets}

Eight of these leaflets (about 50\%) had scores of 12 or 13 which is likely to be the upper limit of readability for this user group, and three contained very complex passages (Table 4). For example.

"If an appeal against conviction has been heard and dismissed, or if the appeal was only against the hospital order, the Crown Court may, if it thinks fit. instead of re-affirming the exdsting sentence, substitute any other penalty the magistrates could have imposed originally."

\section{Information sheets}

The information sheets, listed in Table 5, were written by local mental health trusts to explain new procedures. With the exception of one document, these are all written relatively clearly, with the most complex passages scoring 11 .

\section{Comment}

Written information can be a cost-effective way of providing information to people with mental health problems. However, our study has shown that the language used in information leaflets may be too complex for many users to understand. Perhaps more importantly, written in- formation about patient's rights may also be beyond the comprehension of many patients.

We found some interesting differences between leaflets from different sources. Information leaflets written by local trusts were the most readable. They used short words and short sentences.

Some of the Mental Health Act 1983 leaflets were clearly and simply written but the majority could be simplified. Some contained passages that are likely to be misunderstood by most people, not least those with a mental health problem.

We also looked at information leaflets which described mental health problems and treatments. These were produced by two different bodies - the Royal College of Psychiatrists and MIND. While both contained passages that should be simplified, the MIND leaflets were generally more complex. This is contrary to our expectations, since MIND is a user-led group.

There are various techniques that can be used to improve the readability of writing. Albert \& Chadwick (1992) outline some general principles which are summarised: use type size legible to those with poor visual acuity; avoid overuse of bold or italic type; use short words and short sentences; use illustrations which put across a specific message; avoid unnecessary words; be personal and avoid common use of the passive; use concepts and phrases that all readers will understand; avold unnecessary capitals; and follow rules of grammar and syntax.

With increasing pressures on the time that mental health professionals have to spend with patients, written leaflets are likely to remain a useful source of information about mental illness, services and patient's rights. If this information is to be understandable, it is recommended that the authors pay close attention to the clarity of the language used.

\section{Appendix \\ FOG Test}

(1) Choose a passage of about 100 words, which must end in a full stop.

(2) Find the average sentence length by dividing 100 by the number of sentences.

(3) Find the number of long words, defined as those of three syllables or more, excluding: (a) proper nouns; (b) combinations of easy words, like photocopy: (c) verbs that become three syllables when "-es", "-ing" and "-ed" are added (for example, committed); (d) jargon that the reader will know.

(4) Add the average sentence length to the number of long words. Multiply by 0.4 to get the 'reading score'. 


\section{References}

ALBERT, T. \& CHADWICK, S. (1992) How readable are practice leaflets? British Medical Journal, 305. 1266-1268.

HENESSY, B. (1989) Writing Feature Articles. Oxford: Heinemann.

Peterson, T. (1994) How readable are the hospital information leaflets available to elderly patients? Age and Ageing, 23, 14-16.
*Harriet Humfress, Clinical Psychologist in Training. Sub-Department of Clinical Health Psychology. University College London, Gower Street, London WC1E 6BT; and Ulrike Schmidt, Consultant Psychiatrist, Bethlem \& Maudsley NHS Trust, PACT Team, London

*Correspondence

\title{
Traditional healers and mental illness in Uganda
}

\author{
Emilio Ovuga, Jed Boardman and Elizabeth G. A. O. Oluka
}

\begin{abstract}
Aims and method A cross-sectional, interview survey of the beliefs, knowledge, attitudes and practice towards mental illness of 29 traditional healers in the Pallisa district of Uganda was carried out.

Results Many of the healers had experienced emotional problems that had been treated by other healers. Almost all had a family member who was also a traditional healer. They treated a wide range of conditions and all dealt with mental illness. Most believed that mental disorders were caused by supernatural processes. Many recognised the role of environmental agents. Their diagnosis and management of mental illness was eclectic. The healers were either traditional herbalists or spirit diviners or a mixture of both. Almost all referred patients to the district hospitals and were willing to work with government health services.

Clinical implications The results of the survey suggest the presence of fertile ground on which to build cooperation between traditional healers and medical services. Such cooperation may harness primary care resources more effectively. Sequential or simultaneous models of collaboration (or combinations of both) may be considered. Further work on specific treatments, their outcomes and the evaluation of collaborative models is neөded.
\end{abstract}

Mental disorders contribute significantly to the burden of disease across the globe and constitute a formidable challenge for health services (World Bank, 1993; Abas \& Broadhead, 1994; Desjarlais et al, 1995; Bland, 1996; Jenkins, 1997). Decentralisation of health services has been promoted and primary care services have been identified as playing the vanguard role in providing mental health care (World Health Organization, 1978, 1990; Famuyiwa, 1989; Ustun \& Sartorius, 1995). In developing coun- tries resources are limited, as are the skills and knowledge of primary care personnel (Appleby \& Araya, 1991: Abas \& Broadhead, 1994; Desjarlais et al, 1995). In many countries, traditional healers play an important role in the treatment of mental health problems and these healers may be an important resource in the provision of primary mental health services (Young, 1983; World Health Organization, 1990; Winston et al 1995). Uganda is no exception to this (Boardman \& Ovuga, 1997). This paper reports on a survey of such traditional healers in one area of Uganda.

\section{Traditional healers in Africa}

It has long been recognised that traditional healing practices exist side-by-side with modern medical practice (Lambo, 1956; Orley, 1970; Ademuwagun, 1976; Imperato, 1976). A significant proportion of people seek care from traditional and spiritual healers whom they consult for a range of medical problems. A Nigerian study noted that spiritual healers, traditional healers and general practitioners were the first to be contacted by $13 \%, 19 \%$ and $47 \%$ of patients respectively (Gureje et al, 1995). Those dissatisfied with the results of orthodox medicine often take themselves to traditional healers (Patel et al, 1997a) and a significant proportion of these have psychiatric disorders (Patel et al, 1997b). Few studies have surveyed the practice of traditional healers in relation to mental illness. Odejide et al (1977) examined the characteristics and practices of 53 traditional healers in Ibadan. Nigeria and noted that while they engaged in some undesirable practices, they held a broad concept of psychopathology and provided an important force in the treatment of psychiatric disorders. 